
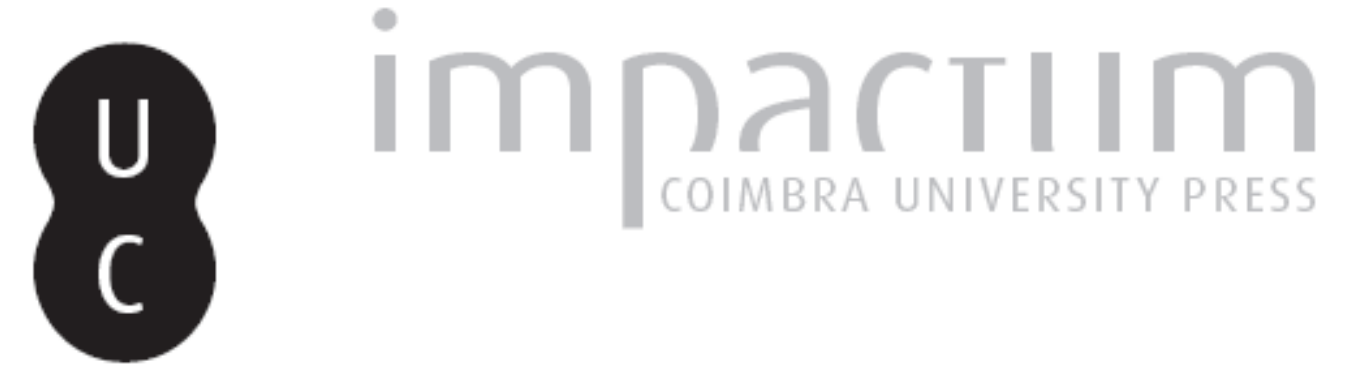
Descobrindo fortunas, contando histórias: panorama patrimonial de portugueses no
Brasil: (Belém, 1870-1909)

Autor(es): $\quad$ Tavares, Anndrea Caroliny da Costa

Publicado por: Imprensa da Universidade de Coimbra

URL persistente:

URI:http://hdl.handle.net/10316.2/43238

DOI:

DOI:https://doi.org/10.14195/0870-4147_48_2

Accessed : $\quad$ 26-Apr-2023 13:04:07

A navegação consulta e descarregamento dos títulos inseridos nas Bibliotecas Digitais UC Digitalis, UC Pombalina e UC Impactum, pressupõem a aceitação plena e sem reservas dos Termos e Condições de Uso destas Bibliotecas Digitais, disponíveis em https://digitalis.uc.pt/pt-pt/termos.

Conforme exposto nos referidos Termos e Condições de Uso, o descarregamento de títulos de acesso restrito requer uma licença válida de autorização devendo o utilizador aceder ao(s) documento(s) a partir de um endereço de IP da instituição detentora da supramencionada licença.

Ao utilizador é apenas permitido o descarregamento para uso pessoal, pelo que o emprego do(s) título(s) descarregado(s) para outro fim, designadamente comercial, carece de autorização do respetivo autor ou editor da obra.

Na medida em que todas as obras da UC Digitalis se encontram protegidas pelo Código do Direito de Autor e Direitos Conexos e demais legislação aplicável, toda a cópia, parcial ou total, deste documento, nos casos em que é legalmente admitida, deverá conter ou fazer-se acompanhar por este aviso.

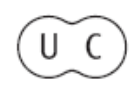




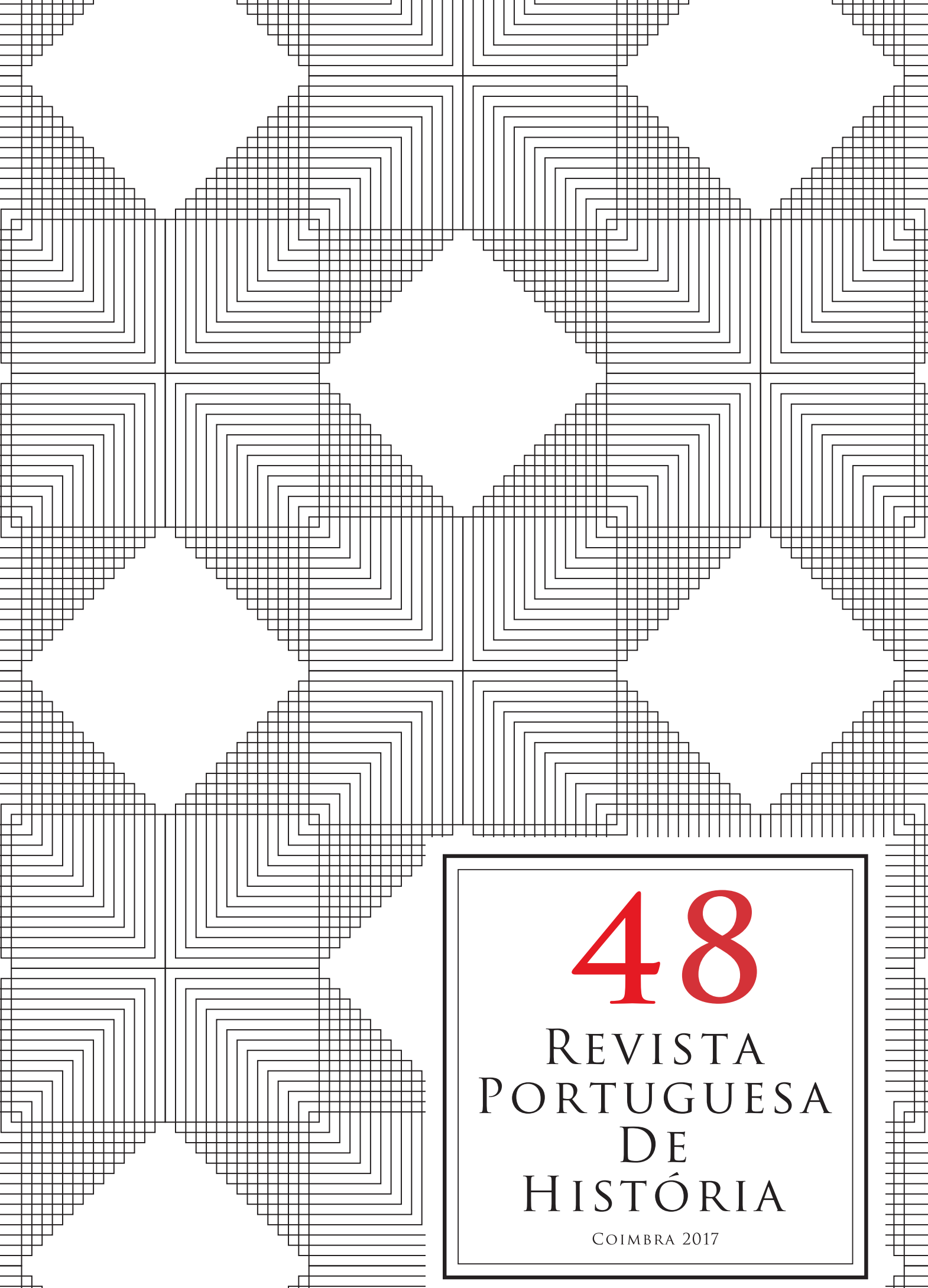




\title{
Descobrindo fortunas, contando histórias: panorama patrimonial de portugueses no Brasil (Belém, 1870-1909)
}

\author{
Discovering fortunes, telling stories: patrimonial panorama \\ of portuguese in Brazil (Belém, 1870-1909)
}

\author{
Anndrea Caroliny da Costa Tavares \\ Programa de Pós Graduação em História Social da Amazônia - UFPA \\ anndreatavares23@hotmail.com
}

Texto recebido em/Text submitted on: 31/01/2017

Texto aprovado em/Text approved on: 11/07/2017

\section{Resumo:}

O presente artigo analisa a composição das fortunas de imigrantes portugueses em Belém, capital da então província do Grão Pará, entre os anos de 1870 a 1909 , caracterizado pela historiografia como o período de boom da economia extrativa da borracha, reconhecida como atrativo aos diferentes grupos de (i) migrantes que se aventuravam para usufruto dos rendimentos por ela alcançados. Fortunas sustentadas sobre novas demandas sociais e econômicas que a borracha haveria de trazer às terras amazônicas, e que evidenciam novas tendências de investimentos, em grande medida, às estruturas modernas do capitalismo, que permaneceram mesmo nos períodos de crise da economia extrativa da borracha, demonstrando a sólida consolidação de novos símbolos de poder e riqueza. $\mathrm{O}$ estudo esteia-se na análise serial de 328 autos cíveis de inventários post mortem e insere-se num período marcado por um crescimento demográfico acentuado, pela reorganização do espaço urbano de Belém e pelo recrudescimento econômico do mesmo espaço.

Palavras Chave:

Belém; Imigração; Portugueses; Borracha; Fortunas.

\section{Abstract:}

This paper analyses the fortune formation of Portuguese immigrants' in Belém, capital of the Grão Pará province, between the years of 1870 to 1909 , period which is characterized by historiography as the boom of the rubber extractive economy, a known attractive to the different groups of migrants that would adventure themselves seeking to take part on the earnings produced by it. Fortunes that where only possible because of the new social and economic demands that were brought over to the Amazon landscape and made clear the new investments trends, remarkably, the modern capitalist structures, ones that remained even in crisis periods of the rubber extractive economy, demonstrating the solid consolidation of the power and wealth new symbols. The paper sustain itself in the serial analyses of 328 post mortem inventory civil suits and is inserted among a period which is trend marked by a sharp demographic growth, by the urban space reorganization and economic rejuvenation of the city of Belém.

Keywords:

Belém; Immigration; Portuguese; Rubber; Fortunes. 


\section{Aspectos gerais da imigração portuguesa em Belém}

A historiografia portuguesa reconhece que a imigração exerce, há mais de um século, uma profunda ação na sociedade lusitana. Tida como um fenômeno antigo, tomou novas formas no século XIX, quando deixou de estar atrelada ao projeto imperial português e tornou-se uma resultante das distorções do desenvolvimento do capitalismo independente, após o rompimento com o antigo regime ${ }^{1}$. De fato, a presença e ocupação portuguesa na Amazônia, onde se localiza o estado do Pará, antiga província do Grão Pará, remete ao período colonial $^{2}$, no entanto daremos ênfase à presença portuguesa durante os meados do século XIX e início do XX, quando esta se fará mais visível nos diferentes espaços da cidade.

Os lusitanos constituíram o grupo mais numeroso de imigrantes que adentraram ao Brasil, com números na faixa dos 1,9 milhão de sujeitos (1822-1950), presentes em praticamente todo o território brasileiro ${ }^{3}$. Apesar disso, a temática que aborda este fluxo para o Brasil consolidou suas bases de estudo recentemente, na medida em que as fontes foram sendo dispostas e os questionamentos, para a ampliação das problemáticas, foram sendo revisitados.

Provenientes de distintas localidades do território português, o que por si já confere pluralidade aos sujeitos, os imigrantes viam no Brasil, sobretudo nos destinos mais conhecidos como São Paulo e Rio de Janeiro e nos emergentes como a Província do Pará, uma oportuna possibilidade de estabelecimento, na perspectiva de inserção nos mercados de trabalho em ascensão, cumular fortuna e retornar a terra natal ou, como ocorreu com uma parcela considerável de imigrantes, apenas sobreviver e esperar ou por uma oportunidade de retorno, ou pelo fim da vida.

Nos últimos anos do século XIX, o Estado do Pará desponta com um dos principais destinos procurado pelos portugueses que partiam para o Brasil. No final do século XIX ele chega a aparecer com um percentual bem maior de escolha para os grupos de imigrantes que a própria cidade de São Paulo, que atraía não somente mão de obra rural, mas também operária e intelectual,

${ }^{1}$ Miriam H. Pereira, A politica portuguesa de emigração (1850-1930), Bauru-Sp, Edusc, 2002, p. 11.

${ }^{2}$ Sobre o processo de ocupação e colonização da Amazônia cf. Rafael Chambouleyron, Povoamento, ocupação e agricultura na Amazônia colonial (1640-1706), Belém, Editora Açaí, 2010.

${ }^{3}$ Maria Izilda Matos, Portugueses: Deslocamentos, Experiências e Cotidiano - São Paulo, séculos XIX e XX, Bauru, SP, Edusc, 2013, p. 34. 
sobretudo pelo crescimento que a economia exportadora do café proporcionava ao cinturão paulista. ${ }^{4}$

Belém foi das cidades que se manteve como a terceira escolha dos portugueses no Brasil, demonstrando assim a atração que a economia da borracha poderia desempenhar para a vinda dos portugueses. Estes sujeitos viveram em cidade portuária, que era ponto de partida de todo tipo de mercadorias para o interior do estado e da região, e porta de saída das exportações da borracha para o mundo. Belém tornara-se uma cidade cosmopolita, onde a expressiva presença dos portugueses promoveu a grande visibilidade de sua cultura até hoje ${ }^{5}$.

A maioria dos imigrantes provinha da região dos minifúndios do médio e Norte de Portugal, deixando aldeias, freguesias, quintas e suas querências ao longo do rio Douro, Minho e Tejo. Quase todos jovens e humildes, eram filhos de agricultores e sitiantes, de numerosa família patriarcal, com rígida educação doméstica e obedientes á tradição e valores familiares. O norte português era reconhecido por sua tradição agrícola, com predomínio dos minifúndios, em posse de proprietários com família numerosa que - sem terem como encaminhar seus filhos para a lavoura, uma vez que as parcelas de terras, com a divisão da herança, se tornaram tão pequenas que eram incapazes de sustentar uma família - viam a solução na emigração para as regiões de colonização, ou com uma comunidade portuguesa que lhes garantisse auxílio na chegada e promovesse sua inserção no meio sócio econômico do novo lugar, como no caso do Pará 6 .

A presença destes imigrantes sempre fora notável na região, seja por sua proporção ou por sua representatividade, uma vez que muitos acabaram adquirindo destaque no meio social, em virtude de sua projeção econômica que, estando de acordo com a nova ordem de organização da economia, relacionava-se às atividades comerciais e beneméritas que exerciam. No que diz respeito à cidade de Belém, esta presença de imigrantes é constatada a partir de várias documentações. Em 1872, o recenseamento apontava a existência de 12\% de estrangeiros na cidade, sendo que desse total os portugueses correspondiam a cerca de $80 \%$ dos imigrantes.

\footnotetext{
${ }^{4}$ Jorge Fernandes Alves, "Lógicas migratórias no Porto oitocentista", in Maria Beatriz Nizza da Silva [et. al], Emigração/Imigração em Portugal, Actas do Colóquio Internacional Emigração/ Imigração em Portugal (séc. XIX e XX), Lisboa, Fragmentos.

${ }^{5}$ Edilza Fontes, Preferem-se português (as): trabalho, cultura e movimento social em Belém do Pará (1885-1914), Tese de Doutorado, Departamento de História do Instituto de Filosofia e Ciências Humanas da Universidade Estadual de Campinas, Campinas, 2002.

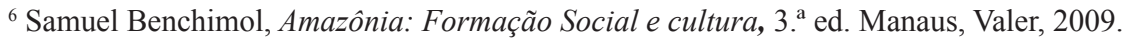


Os registros de casamento das Paróquias da Sé e de Nazaré analisados por Cristina Cancela, entre 1870 a 1920, igualmente mencionam o expressivo número de estrangeiros nos autos de casamento na Sé chegando a $10 \%$ e $6 \%$ na paróquia de Nazaré. Os portugueses predominam entre os estrangeiros nos registros das duas paróquias, seguidos dos espanhóis e sírio-libaneses ${ }^{7}$. Esta presença pode ter sido ainda maior se levarmos em conta o possível impacto causado pela Grande Naturalização de 1891 na população de origem portuguesa ${ }^{8}$, o que pode ter ocasionado uma invisibilidade de parte destes sujeitos. O possível impacto refere-se detidamente a dois aspectos principais: primeiramente a representatividade dos "casamentos portugueses", em comparação à tendência geral, pode ser mais impactante do que mensuramos, isto porque diversos noivos descritos como brasileiros poderiam ser, na realidade, de origem portuguesa. Em segundo lugar, porque a naturalização poderia tornar invisíveis diversos “casamentos portugueses", onde os noivos possuíssem mais de 35 anos de idade, pois já poderiam estar naturalizados no instante do casamento9.

Os dados acerca do movimento imigratório no porto de Belém, no século XX e que se encontram registados no Anuário Estatístico do Brasil de 1912, confirmam a representatividade da imigração na Amazônia. De acordo com o Anuário Estatístico do Brasil, entre os anos de 1908 e 1910, chegaram a Belém aproximadamente 13.500 estrangeiros de diversos países, sobressaindo os portugueses com uma porcentagem de 48,67\%, à frente dos espanhóis (15,98\%), ingleses $(7,18 \%)$, turcos-árabes $(4,69 \%)$ e dos italianos $(4,15 \%)$. O crescimento econômico da Amazônia, decorrente da elevação dos preços da borracha nesse período, pode ter constituído fator motivador dessa expressiva imigração ${ }^{10}$.

Os imigrantes portugueses eram desejáveis pelo Governo do Pará, sobretudo pelo forte vínculo entre o Pará e Portugal, a propaganda feita pelos governos brasileiro e paraense, a proximidade cultural e a sua facilidade de adaptação à vida na capital, além da fama de pacíficos e morigerados. Não causava nenhum

${ }^{7}$ Cristina Cancela, Casamento e família em uma capital amazônica (Belém 1870-1920), Belém, Ed. Açaí, 2011.

${ }^{8}$ Sobre a Grande Naturalização de portugueses no Brasil, cf. José Sacchetta Ramos Mendes, Laços de Sangue: Privilégios e Intolerância à Imigração Portuguesa no Brasil (1822-1945), São Paulo, Editora da Universidade de São Paulo, Fapesp, 2011.

${ }^{9}$ Cristina Cancela e Daniel Barroso, "Imigração portuguesa e Casamento: Um olhar a partir do gênero, da geração e da atividade (Belém, 1908-1920)", in Maria de Nazaré Sarges [et. al]. Entre Mares: O Brasil dos Portugueses, Belém, Editora Paka-Tatu, 2010, p. 32-41.

${ }^{10}$ Marília Emmi, A Amazônia como destino das migrações internacionais do final do século XIX ao início do século XX: o caso dos portugueses, XVII Encontro Nacional de Estudos Populacionais, ABEP Caxambú-MG. http://www.abep.nepo.unicamp.br/encontro2010/docs_pdf/ tema_1/abep2010_2086.pdf. 
estranhamento a presença dos lusitanos na cidade, fruto da intensa colonização e da forte ligação com Lisboa, tanto que o Pará foi a ultima província brasileira a aderir à Independência do Brasil de Portugal, em $1823^{11}$.

Os finais do século XIX e início do XX também são conhecidos pela consolidação, expansão e decadência da economia extrativa do látex, a borracha $^{12}$, considerada uma das, se não a principal, força motriz para a vinda de (i)migrantes à Amazônia, entre eles os portugueses, que viam no trabalho com a borracha, ou com as atividades impulsionadas (in)diretamente por ela, a possibilidade de novos arranjos profissionais. Os anos de 1870 a 1909 são referidos como o momento de consolidação e expansão desta economia na região, também conhecido como boom da borracha. Em 1882, a produção dos gomais amazônicos já influía consideravelmente no processo econômico do Império, ocupando o terceiro lugar no quadro de exportação, apenas o café e o açúcar se lhe mantinham à frente ${ }^{13}$. Com o aumento das exportações de borracha e a alta dependência em que a economia regional mantinha com tais, às receitas públicas só lhes restava crescer, a liquidez econômica foi sentida na ampliação das estruturas urbanas da capital da província, no melhoramento dos serviços públicos, na ampliação das redes bancárias e seguradoras, pompas e riquezas que trariam à Amazônia os ares da Belle Époque $e^{14}$.

\section{A fortuna portuguesa no Boom da Borracha}

Quando em 1870 a borracha alcança equilíbrio nas pautas de exportação e os preços estão mais estáveis, sente-se o crescimento acelerado do comércio, dos bancos e estabelecimentos afins, fazendo com que a fortuna estivesse ligada aos novos elementos constituintes da economia amazônica. Weinstein considera que os últimos anos da década de 1870 foram os que assinalaram o início da

${ }^{11}$ Maria de Nazaré Sarges e Cauê Morgado, "Os portugueses nos autos judiciários: sociabilidades e tensões”, in Maria de Nazaré Sarges [et. al], Entre Mares: O Brasil dos Portugueses, Belém, Pakatatu, 2010.

${ }^{12}$ A borracha é o produto final dentro da cadeia de exploração do látex, a partir da hévea brasiliensis, árvore nativa amazônica, também conhecida por seringueira. A seiva extraída da árvore, após passar por uma série de processos químicos, é transformada em borracha, matéria prima para uma diversidade de indústrias, à época de seu boom na Amazônia era utilizada, principalmente, nas indústrias automobilísticas norte americanas e europeias.

${ }^{13}$ Ernesto Cruz, História de Belém, Belém, Universidade Federal do Pará, 1973, p. 310-311.

${ }^{14}$ Sobre a Belle Époque Amazônica, cf. Maria de Nazaré Sarges, Riquezas produzindo a Belle Époque (1870-1912), Belém, Paka Tatu, 2010. 
expansão da borracha. O volume de produção, na década de 1880, quase que duplicou, depois de ter a maior alta nos anos de 1860.

As fortunas neste período tornam-se vultuosas, embora não sejam compostas por uma grande variedade de bens, ou seja, concentravam-se em poucos investimentos.

Tabela 1 - Valores das fortunas nos anos de 1870 a 1909 (réis)

\begin{tabular}{|c|c|c|}
\hline Montantes & Quantidade & Percentual (\%) \\
\hline Sem indicação & 91 & 27,7 \\
\hline Abaixo de 9:999\$999 & 52 & 15,9 \\
\hline 10:000\$000-39:999\$999 & 64 & 19,5 \\
\hline 40:000\$000-69:999\$999 & 26 & 7,9 \\
\hline $70: 000 \$ 000-99: 999 \$ 999$ & 23 & 7,0 \\
\hline Acima de 100:000\$000 & 72 & 22,0 \\
\hline Total & 328 & 100,0 \\
\hline
\end{tabular}

Fontes: Inventários post mortem do Centro de Memória da Amazônia. Cartórios Santiago, Leão, Sarmento, Fabiliano Lobato e Odon Rhossard (1870-1909).

Chamamos atenção para as fortunas com montantes acima dos 100 contos de réis, um total de 72 , entre as quais 48 possuíam relação direta com o setor terciário da economia, dividindo-se entre firmas comerciais, casas de comércio, comércio de ações, lojas varejistas, capitalistas, entre outros. O que confirma a importância que o comércio ganhou no passar dos anos e com o crescimento da economia na cidade de Belém, independente do gênero, tornara-se uma das principais, se não a principal, fonte de sustento dos sujeitos e famílias na capital da província do Pará, de nossa amostra. O investimento em imóveis, sobretudo terrenos e casas, será muito frequente. Entre os 72 sujeitos, 44 investiram em propriedade de casas, 27 em terrenos e 24 investiam em ambos.

A maior fortuna nessa faixa pertencia a Domingos José Dias, Visconde de São Domingos, calculada em 1.530:049\$600 réis $(77.572 £)^{15}$. Lino de Macêdo o menciona como o "decano da colônia portuguesa e seu respeitado mentor,

\footnotetext{
${ }^{15}$ Inventário de Domingos José Dias, ano de 1904. Centro de Memória da Amazônia, 11. ${ }^{\text {a Vara }}$ Cível - Cartório Fabiliano Lobato.
} 
fora antigo negociante aviador ${ }^{16}$ onde lograva fartos meios de fortuna. $\mathrm{Na}$ Beneficente Portuguesa ${ }^{17}$ exerceu durante anos a sua presidência, anos seguidos presidiu na Associação Comercial de Belém, foi membro da comissão consultiva do consulado português em Belém, até seu falecimento" ${ }^{18}$. Em 1890, estava na diretoria do Banco de Belém, um dos frutos da ampliação das estruturas bancárias que a borracha promoveu no Pará ${ }^{19}$. Seu inventário encontra-se incompleto, o que não nos permite visualizar em que investia o português, no entanto imaginamos que a maior parte de sua riqueza fosse oriunda dos lucros de sua firma aviadora.

O impacto demográfico e econômico do negócio da borracha só viria a ser plenamente sentido com o advento dos "anos dourados" da Amazônia, entre 1880 e 1910, mas desde os meados do XIX as exportações de borracha estavam tendo efeito claramente perceptível sobre as "estatísticas vitais" do Pará $^{20}$. No relatório de 1889 o Presidente da Província Antônio Braga lamenta a desorganização dos órgãos ligados à migração, que não souberam aproveitar

${ }^{16}$ Aviador era um dos vocativos recebidos pelos donos das Casas Aviadoras, representante financeiro e legal dos seringais nas grandes capitais, como Belém e Manaus. Recebiam a borracha e atendiam aos pedidos de mercadoria para sustento dos trabalhadores na floresta. Providenciavam o transporte e a distribuição da mão de obra para os seringais, espécie de recrutadores.

${ }^{17}$ No ano de 1854, surgiu a ideia, entre alguns portugueses residentes em Belém, da criação de uma sociedade beneficente que servisse de amparo aos seus associados nas provações da vida e enfermidade. À frente do projeto estava Francisco Gonçalves de Medeiros Branco, empregado no comércio em Belém. Em setembro do mesmo ano, reuniram-se com Medeiros Branco um grupo de compatriotas, com o objetivo de tratar da instalação da sociedade beneficente. Após dias, foram enfim apresentados os estatutos, e a então sociedade foi nomeada como Beneficente, que tinha por fim essencial, reunir e socorrer fraternalmente os seus sócios, para além de questões de saúde, como diária de 600 a 1.200 réis a sócios desempregados ou doentes, pagamento de passagens para fora da província no caso de moléstia, desemprego ou perseguição, enterro decente aos mortos, entre outros. Mesmo com a escolha anterior de alguns nomes que pudessem dirigir, temporariamente, a recém sociedade, na mesma reunião de apresentação do nome, em 8 de outubro, foi escolhido o primeiro corpo oficial de dirigentes, tendo Medeiros Branco como seu primeiro presidente. A joia de admissão a Beneficente era no valor de 20.000 réis e a mensalidade no valor de 1.000 réis, in História da Sociedade Portuguesa de Beneficente do Pará. Pará, Gillet de Torres \& $C^{\text {a }}, 1914$, p. 7-22.

${ }^{18}$ Lino de Macedo, Amazônia: Repositório Alphabetico de termos, descrições de localidades, homens notáveis, aminaes, aves, peixes, lendas, costumes, clima, população, riquezas, monumentos, progressos, tarifas, indicações úteis, propriedades e curiosidades do grandioso vale do Amazonas, Lisboa, Typ. Adolpho Mendonça, 1906, p. 269-2.

${ }^{19}$ Pinto Barbosa, Almanak do Pará: Commercial, Industrial e Administrativo, Pará, Typ. dos Editores Proprietários Pinto Barbosa \& C., 1890, p. 147.

${ }^{20}$ Bárbara Weinstein, A borracha na Amazônia: expansão e decadência (1850-1920), São Paulo, HUCITEC/EDUSP, 1993, p. 55-56. 
melhor "os retirantes das províncias flagelados pela seca"21 que já disputavam espaço na província do Pará com a leva de imigrantes estrangeiros, de maioria portuguesa $^{22}$.

A expansão da economia da borracha trouxe consigo não somente a evolução demográfica, mas também a necessidade da cidade proporcionar a essa população estruturas básicas de acomodação, tornando a demanda por moradia e por melhores estruturas urbanas acentuada. Demandas evidentes pelo número de portugueses que declararam a posse de casas na cidade neste período de crescimento acentuado do meio urbano, conforme se pode observar no gráfico seguinte.

\section{Gráfico 1 - Bens Imóveis (Belém, 1870-1909)}

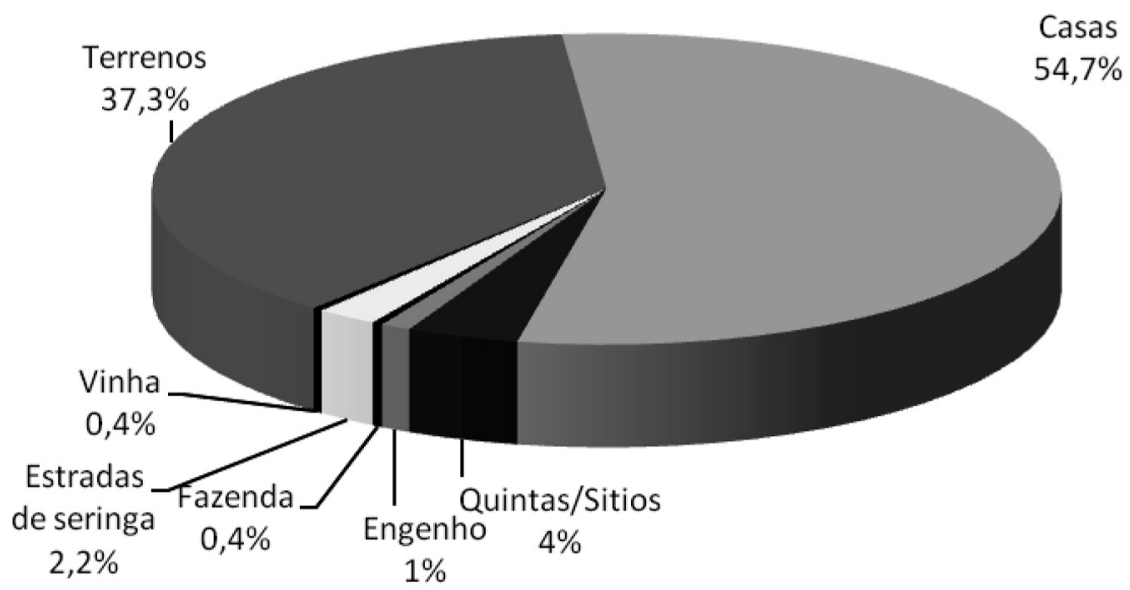

Fontes: Inventários post mortem do Centro de Memória da Amazônia. Cartórios

Santiago, Leão, Sarmento, Fabiliano Lobato e Odon Rhossard (1870-1909)

As casas, que incluem sobrados, prédios térreos, quarto de casas, representam $54,7 \%$ dos bens, compondo a fortuna de um total de 151 imigrantes. Entre a comunidade portuguesa se fala que todo português gosta de ter sua própria casa,

${ }^{21}$ Relatório, Presidente Antonio Jose Ferreira Braga, em 18 de setembro de 1889. Typ. de A. Fructuoso da Costa, p, 19.

${ }^{22}$ Sobre a migração nordestina para o Pará durante o século XIX e XX, cf. Franciane Lacerda, Migrantes cearenses no Pará: Faces da sobrevivência (1889-1916), Belém, Editora Açaí, 2010. 
seu lar, porém neste caso, a posse de mais de um bem habitacional representa uma quantia a mais na renda familiar, se não sua renda total, especialmente em uma cidade demograficamente crescente. Os imóveis se configuravam na alternativa mais viável de investimento, tendo em vista as oscilações do sistema de crédito bancário que geravam desconfiança entre os proprietários ${ }^{23}$. Embora os investimentos em ações bancárias, firmas e prestadoras de serviços também estejam entre os mais frequentes e numerosos investimentos encontrados.

Em muitos casos, como aponta Weinstein, muitos lotes em áreas suburbanas que haviam sido adquiridos por uma família décadas antes da expansão acelerada da cidade tornavam-se imóveis de qualidade e bem localizados na medida em que a cidade ia além dos limites iniciais. Comerciantes ou não, indivíduos com certo cabedal começaram a adquirir residências, terrenos, prédios comerciais em zonas não desenvolvidas, tornando-se, em muitos casos, os únicos bens descritos nos inventários ${ }^{24}$.

Em 1877, o português Antônio da Silva Maia, natural do Porto, declara a posse de 28 imóveis na cidade de Belém. Sem informar sua ocupação, o inventariado leva a crer que sua renda provinha dos aluguéis dos numerosos imóveis que possuía. As propriedades estavam localizadas em 12 endereços distintos, incluindo a Travessa São Mateus (atual Pe. Eutíquio, com 4 casas), Rua Formosa (com 3 casas), Rua dos Mártires (atual 28 de Setembro, com 3 casas), Rua do Bailique (com 3 casas) e a Travessa das Mercês (atual Frutuoso Guimarães, com 3 casas). Portanto, boa parte dessas casas estava localizada em ruas das áreas de comércio da cidade ou próximas a elas, como a dos Mártires e das Mercês, esta ultima havia recebido o "tão reclamado" calçamento em paralelepípedos no ano de 1873, o que insinua uma valorização dos imóveis em virtude de beneficiamentos ${ }^{25}$. Imóveis em áreas iniciais de ocupação da cidade ${ }^{26}$.

Um dos imóveis situados na travessa São Mateus era um sobrado de dois andares, sob o n. ${ }^{\circ}$ 5A. No primeiro andar havia duas janelas com grades de ferro, alcova, varanda, dois quartos, dispensa e cozinha, todo o espaço forrado, exceto a cozinha. Neste andar o sobrado ainda contava com um pavimento para armazém, com paredes de pedra e cal. O segundo andar tinha sala, alcova e

${ }^{23}$ Cristina Cancela, Casamento e familia ..., cit., p. 306.

${ }^{24}$ Barbára Weinstein, A Borracha na Amazônia ..., cit., p. 106.

${ }^{25}$ Relatório com que o excellentissimo senhor doutor Domingos José da Cunha Junior, presidente da província, abriu a 2. ${ }^{\mathrm{a}}$ sessão da 18. ${ }^{\mathrm{a}}$ legislatura da Assembléa Legislativa Provincial em 1. ${ }^{\circ}$ de julho de 1873. Pará, Typ. do Diario do Gram-Pará, 1873, p. 36.

${ }^{26}$ Inventário de Antônio da Silva Maia, ano de 1877. Centro de Memória da Amazônia. 2. ${ }^{a}$ Vara Cível - Cartório Odon Rhossard. 
varanda, espaços todos forrados. Paredes de pedra e cal, ares de perna manca e ripas, medindo 13 braças e um palmo de frente por 11 braças e meia de fundos, avaliado em 16:000\$000 réis (1.697 £), o maior valor atribuído entre os tantos imóveis. Ainda na São Mateus, o português dispunha de uma casa térrea, sem número, com alcova, varanda, puchada ${ }^{27}$ com três quartos, cozinha e saguão, tendo ainda dois fornos para padeiro, ares de perna manca, ripas e caibros, toda assoalhada, medindo duas braças e seis palmos de frente com dezessete braças de fundo, avaliada em 6:000\$000 réis (636 £).

Percebemos nas avaliações de Antônio que não bastava o imóvel ser bem localizado, importava também a utilidade que este poderia ter. Embora o segundo tivesse os fornos para padaria, o primeiro possuía espaço para armazém, o que em uma área próxima ao centro comercial, como a Rua São Mateus, poderia agregar mais lucro, especialmente pela locação do espaço.

Entre a herança deixada por Antônio de Araújo Sampaio ${ }^{28}$, em inventário aberto em 1905, além de ações encontramos dinheiro proveniente dos alugueis de imóveis em Belém, localizados em São Brás, recente área de expansão dos domínios do centro urbano. O processo de Araújo Sampaio não descreve os imóveis, apenas menciona os limites dos terrenos. Um deles localizado em São Braz possuía dois metros de frente por vinte e três metros de fundos, avaliado em 4:000\$000 réis $(261 £)$. Nos autos, o valor cobrado em aluguéis correspondia a $207 \$ 197$ réis $(13 £)$.

Em 1906, Adriano Cândido Puga destinava dois de seus três prédios para aluguel, porém não especifica quais eram os alugados: se os que ficavam na Oliveira Belo (letras A e B) ou o que estava próximo à Travessa Oriental do Mercado, n. ${ }^{\circ}$, na área comercial ${ }^{29}$.

Além das casas, a posse de terrenos também era significativa em meio aos portugueses, sejam terrenos ainda vazios ou com alguma benfeitoria. Um total de 103 indivíduos, que representam 37,3\% de nossa amostra, apostavam seus investimentos em terrenos, tanto em áreas urbanas, quanto em áreas rurais.

O maior investidor em terrenos era José Coelho da Silva Junior, comerciante que possuía 24 posses de terras, todas em Portugal, com árvores frutíferas, uvas,

\footnotetext{
${ }^{27}$ Puchada corresponde a uma construção simples, geralmente externa à construção do imóvel para alocação de compartimentos extras.

${ }^{28}$ Inventário de Antônio de Araújo Sampaio, ano de 1905. Centro de Memória da Amazônia.

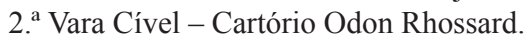

${ }^{29}$ Inventário de Adriano Cândido Puga, ano de 1906. Centro de Memória da Amazônia.

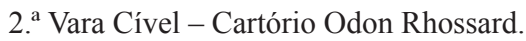


carvalhos, pinheiro e terras incultas ${ }^{30}$. Embora os bens estivessem em Portugal, eles foram citados no traslado de seu testamento, em anexo ao inventário, a fim de declarar sua existência, que depois deveriam ser divididos entre os herdeiros, conforme a vontade estabelecida em testamento.

Antônio Augusto Bento de Almeida Júnior, natural do distrito de Guarda, possuía terrenos ao longo da Estrada de Ferro de Bragança e próximos uns dos outros. À margem esquerda estava o lote n. ${ }^{\circ} 86$ onde mantinha um barracão, contíguo a um engenho, com pequena fábrica de rapadura e alambiques para a água. À margem direita estavam os lotes de número 86 e 88 , o primeiro com uma casa e o segundo com barracas. O mesmo investimento foi feito por José Henriques de Oliveira, com 8 lotes ao longo da estrada de ferro, todas no valor de 300:000 réis ${ }^{31}$. Nota-se a posse de bens dos portugueses em áreas recentes de expansão ao entorno de Belém, neste caso a Estrada de Ferro de Bragança ${ }^{32}$.

As quintas/sítios contabilizam 11 propriedades descritas. As quintas ou sítios na região amazônica exprimem o mesmo conceito que aquelas dos arredores de Lisboa, a exemplo ${ }^{33}$. Podendo materializar aspectos de uma aristocracia ou da elite comercial, que buscavam lugares de descanso, sempre jardinados, demonstrando o afastamento dos alvoroçados ares da cidade.

Dos 11 portugueses com essas propriedades, 6 informavam suas localizações. Quatro mantinham suas propriedades dentro da então Província do Pará, nas regiões de Chaves, Acará, Ourém e Bujarú, sem informações adicionais sobre suas explorações. Dois deles mantinham quintas em Portugal, o comerciante Manoel José Pereira Junior ${ }^{34}$ e o proprietário José Pereira Barbosa ${ }^{35}$, ambas no distrito de Viana do Castelo de onde eram naturais. Por estes bens poderiam

${ }^{30}$ Inventário de José Coelho da Silva Junior, ano de 1880. Centro de Memória da Amazônia. 11. ${ }^{\text {a }}$ Vara Cível - Cartório Fabiliano Lobato.

${ }^{31}$ Inventário de José Henriques de Oliveira, ano de 1897. Centro de Memória da Amazônia. 11. ${ }^{a}$ Vara Cível - Cartório Fabiliano Lobato.

${ }^{32}$ Com início de sua instalação no ano de 1883 , considerada pelos poderes públicos o grande marco de desenvolvimento dessa região, ligando Belém à cidade de Bragança, com uma distância de aproximadamente 293 quilômetros, em uma área bem pouco povoada, para tanto o então presidente da província, Barão de Maracaju, acreditava que esta seria uma estratégia de atrair povoamentos e civilização nas áreas de percurso do trem.

${ }^{33}$ Rui Cascão, "Modos de habitar", in José Mattoso (dir.) e Irene Vaquinhas (org.). História da Vida Privada em Portugal - A Época Contemporânea, Temas e Debates/Círculo de Leitores, 2011, p. 27.

${ }^{34}$ Inventário de Manoel José Pereira Junior, ano de 1886. Centro de Memória da Amazônia. 2. ${ }^{a}$ Vara Cível - Cartório Odon Rhossard.

${ }^{35}$ Inventário de José Pereira Barbosa, ano de 1904. Centro de Memória da Amazônia. 11. ${ }^{\text {a Vara }}$ Cível - Cartório Fabiliano Lobato. 
agregar capital simbólico, junto não apenas à comunidade lusa local mas também com os que viviam em Portugal, sustentado no mito de riqueza que girava em torno do Brasil, ou mesmo a manutenção dos laços com a terra natal e o apoio ao sustento da família que lá ainda fixava moradia. Os bens portugueses eram referidos, mas não eram partilhados nos autos do processo aberto em terras brasileiras.

Em torno desse ideário de manter laços com a terra natal, podemos inserir ainda a perspectiva do retorno, seja ele temporário ou definitivo, uma vez que para muitos portugueses a ideia era migrar e agregar rendimentos que pudessem garantir junto ao retorno melhores condições de vida para ele e para os seus. Como esclarece Alves, no refluxo do movimento migratório, muitos emigrantes voltam episódica ou definitivamente. Este, o retornado sem capital acumulado, mais discreto, procurando fazer passar despercebido o seu infortúnio ou evidenciando a doença que lhe corroeu o corpo e o ânimo. Aquele marcado pelo sucesso, "com sotaque na fala, indumentado de calças brancas, casado de ganga, chapéu de Chili, adereçado de cadeia de oiro e anel de brilhante" num exotismo de modos que o romantismo fixará para sempre, recriando o estereótipo do brasileiro $^{36}$. Na quinta de José Pereira Barbosa ainda havia uma morada de casas e um campo de lavrar com vinha, o que deveria ajudar no sustento da família na terra natal.

Os engenhos representam $1 \%$ da amostra, no total de 3 unidades. Localizados na região de Acará, Distrito de Benfica e Estrada de Bragança, não sabemos sua principal produção, uma vez que nos processos apenas eram citados como "engenhos", exceto o na Estrada de Bragança voltado para a fabricação de água ardente e rapadura ${ }^{37}$. Em relação à região do Acará, há tempos que esta área havia sido ocupada por diversos sujeitos, estrangeiros e nacionais, em virtude da maior oferta de terras em áreas do interior e a facilidade de circulação entre elas e a capital. Na mesma região, foram doadas, pelo menos, cinco sesmarias, que revelam uma lógica particular de ocupação do território pela agricultura, a partir do sistema fluvial composto pelos rios Acará, Moju, Capim e Guamá ${ }^{38}$.

${ }^{36}$ Jorge Alves, Os brasileiros: emigração e retorno no Porto Oitocentista. (Dissertação), Faculdade de Letras da Universidade do Porto, 1993, p. 12.

37 Água ardente é uma bebida de teor alcoólico elevado obtida pela destilação do caldo da cana-de-açúcar, do vinho, do bagaço de uvas, de cereais, raízes, tubérculos, frutos e outros produtos vegetais doces, depois de fermentados. A Rapadura é o açúcar retirado após a fervura do caldo da cana, solidificado, vendida em forma de tabletes, utilizada em receitas e remédios.

${ }^{38}$ Rafael Chambouleyron, Povoamento, ocupação e agricultura na Amazônia colonial (1640-1706), 1. ${ }^{a}$ ed. Belém, Açaí/Centro de Memória da Amazônia/PPHIST-UFPA, 2010, p. 104. 
As fazendas se resumiam em duas unidades: uma em Mosqueiro e outra em Soure, na Ilha do Marajó. Nesta última área, definida por Weinstein como a zona preferida para a pecuária, sobretudo a região leste, era possível encontrar pastagens prontas para serem utilizadas na criação de gado ${ }^{39}$. Na descrição da fazenda de Manoel José Lourenço de Carvalho, em Mosqueiro, são descritos apenas bovinos. $\mathrm{O}$ inventário, porém, não traz o valor do montante final da fortuna $^{40}$. Em Soure, na propriedade de Fernando Maria da Cunha são descritos animais bovinos e cavalares, tendo montante calculado em 484:930\$128 réis $(38 £)^{41}$.

Nesse período, a novidade dos bens inventariados são as estradas de seringa, que aparecem em 6 processos, num total de 329 estradas. Embora pareça um número muito pequeno em relação à amostra, são importantes por nos apontarem o investimento direto na borracha, mas também a posse de terras em áreas rurais, que estavam tradicionalmente concentradas em mãos de nacionais, principalmente na região do Marajó, área tradicionalmente de sesmarias, heranças de gerações, limitando sua posse por estrangeiros. Portanto, a existência de inventariados com posses de fazendas, particularmente na Ilha do Marajó, mostra os poucos que conseguiram comprar terras e não apenas viver da abertura de firmas comerciais. Até mesmo por serem os portugueses mais frequentes no setor terciário ligado à borracha com aviamentos, consignações e comissões e, não na extração da goma elástica. Este é o caso de um dos maiores comerciantes de borracha do Pará, Bento Rebelo de Andrade, sócio na firma Darlindo Rocha \& Companhia, voltada para o comércio de aviamento, importações, comissões e outras transações, com sede em Belém. ${ }^{42}$.

No Pará, as maiores concentrações da hevea brasiliensis eram encontradas na região das ilhas e ao longo dos rios Xingu e Tapajós ${ }^{43}$. Entre os 6 portugueses que possuíam em suas propriedades estradas de seringa, três estavam na Ilha do Marajó, com seringueiras registradas no município de Anajás e um em Chaves. O coronel José Antônio de Resende Júnior, natural de Aveiro, possuía 235 pés da hevea no seu seringal, junto com casa de vivenda e um barracão, seringal avaliado em 94:000\$000 réis (4.668 £), cada seringueira na quantia de

${ }^{39}$ Bárbara Weinstein, A Borracha na Amazônia ..., cit., p. 57.

${ }^{40}$ Inventário de Manoel José Lourenço de Carvalho, ano de 1885. Centro de Memória da Amazônia. 11. ${ }^{a}$ Vara Cível - Cartório Fabiliano Lobato.

${ }^{41}$ Inventário de Fernando Maria da Cunha, ano de 1887. Centro de Memória da Amazônia. 11. ${ }^{\text {a }}$ Vara Cível - Cartório Fabiliano Lobato.

${ }^{42}$ Inventário de Bento Rebelo de Andrade, ano de 1900. Centro de Memória da Amazônia.

2. ${ }^{\text {a }}$ Vara Cível - Cartório Odon Rhossard.

${ }^{43}$ Bárbara Weinstein, A Borracha na Amazônia ..., cit., p. 57. 
$400 \$ 000$ réis $(19 £)^{44}$, e o comerciante Antônio Alves da Silva Cunha com 26 estradas registradas na Intendência de Anajás, comarca de Afuá, sem avaliação quanto o valor do seringal ${ }^{45}$.

Ainda nessa área, Antônio Joaquim da Cruz mantinha 14 estradas na Ilha Caviana, pertencente a Chaves. Percebemos então uma formação triangular no cinturão de exploração do látex na Ilha do Marajó por estes sujeitos, circuncidando as localidades de Anajás, Chaves, Afuá e a Ilha Caviana, pontos distantes da capital, como observamos na imagem.

\section{Imagem 1 - Ilha do Marajó e Municípios}

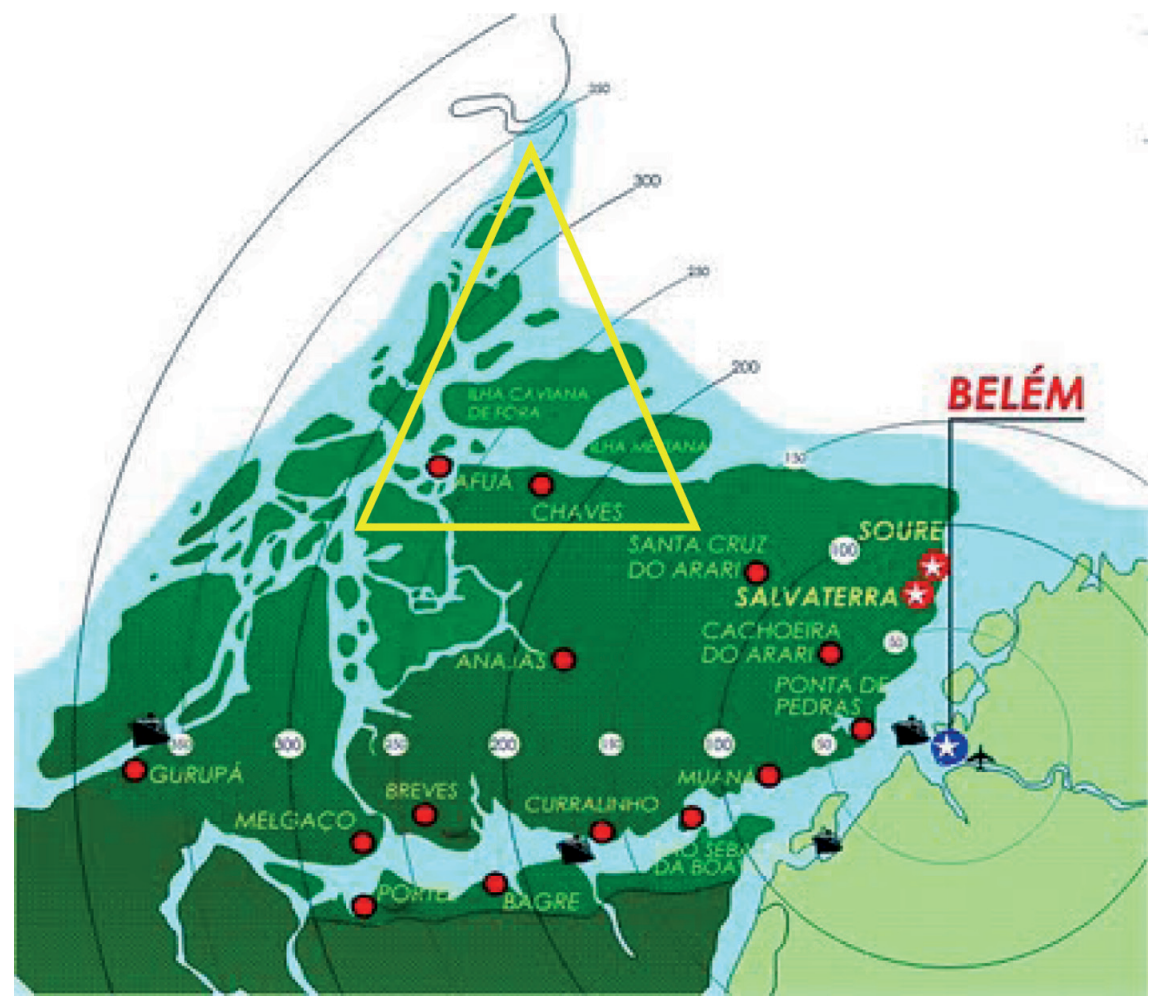

Fonte: http// agracadodia.blogspot.com. Acessado em 17/11/2015, grifo da autora.

${ }^{44}$ Inventário de José Antônio de Resende, ano de 1903. Centro de Memória da Amazônia.

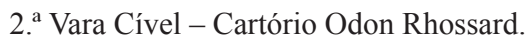

${ }^{45}$ Inventário de Antônio Alves da Silva Cunha, ano de 1904. Centro de Memória da Amazônia.

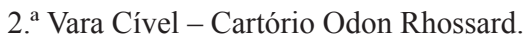


Quantos aos bens móveis, principalmente os investimentos financeiros, percebemos uma expressiva presença, sobretudo do dinheiro $(32,8 \%$ da amostra, correspondente a 135 portugueses), ações comerciais (19\%, 78 investidores), seguida das letras (27 investidores, 6,6 \% da amostra), dívidas ativas $(6,1 \%$ da amostra, correspondendo a 25 investidores) e finalmente as apólices diversas $(3,2 \%, 13$ portugueses), além das firmas comerciais (16,3\% dos portugueses, 67 investidores), conforme o gráfico seguinte.

\section{Gráfico 2 - Bens Móveis - Investimentos financeiros (Belém, 1870-1909)}

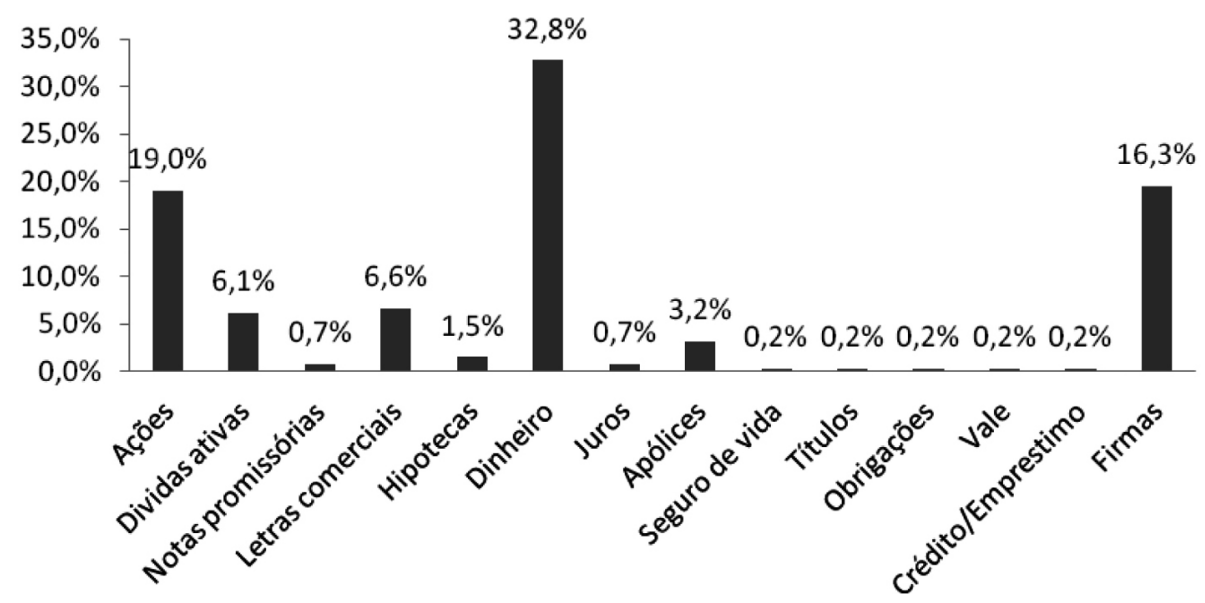

Fontes: Inventários post mortem do Centro de Memória da Amazônia. Cartórios

Santiago, Leão, Sarmento, Fabiliano Lobato e Odon Rhossard (1870-1909)

Mesmo em meio ao crescimento econômico que Belém vivenciava, muitos paraenses e estrangeiros ricos com restrições de conseguir crédito a longo prazo que, justificando pelo capital escasso e fragmentado em pequenas fortunas particulares e ainda a escassez de recursos privados o baixo nível de progresso agrícola e industrial da região, optaram por investimentos prósperos provenientes dos negócios da borracha, como em ações de banco que chegavam a oferecer rendimentos bem maiores e mais rápidos, juntamente com investimentos nos imóveis urbanos de onde os lucros eram mais viáveis ${ }^{46}$. Até o ano de 1880, havia apenas um banco de capital na região, o Banco Comercial do Pará, com um capital de mil contos até os anos de 1870, valor insuficiente para atender à demanda comercial que a comunidade mercantil do Pará precisava à época.

\footnotetext{
${ }^{46}$ Bárbara Weinstein, A Borracha na Amazônia ..., cit., p. 107.
} 
Mobilizados pela expansão econômica promovida pela borracha, foram fundados outros cinco novos bancos com capitais investidos do Pará e do Amazonas. Essa expansão do setor de crédito não é restrita à região amazônica e à borracha, em regiões como o Vale do Paraíba paulista, sobretudo a partir da década de 1850 com o estabelecimento do Código Comercial e da legislação hipotecária de $1864 / 65^{47}$.

Mudanças que condicionaram e foram condicionadas pelas transformações econômicas da economia brasileira de maneira geral. Marcondes destaca que o avanço do capitalismo no país promoveu alterações nas condições de financiamento, reduzindo o espaço do "capital comercial e/ou usuário e incentivando o capital bancário". A modernização do mercado de capitais, que inclui bancos, sociedades acionárias, entre outros, encontrava-se limitada pelas imperfeições de mercado (elevados custos de transação e assimetria de informações, principalmente em regiões distantes dos centros comerciais) que asseguravam a predominância do crédito pessoal, pautado em uma rede de relações de amizade, parentesco e dependência pessoal, que facilitavam na obtenção de informações sobre o devedor e no controle dos débitos ${ }^{48}$.

Longe de limitarem seus investimentos em ações bancárias, os portugueses aproveitaram a remodelação da cidade para garantir boas aplicações na área de serviços públicos. Um dos empreendimentos mais importantes nessa área talvez tenha sido a Companhia das Águas do Grão-Pará, que dirigiu a construção, o funcionamento e a manutenção do abastecimento de água em Belém durante os anos de 1881 a 1895. Com ações no valor de 100 mil réis a companhia conseguiu atrair um grande número de acionistas, como José Augusto Corrêa, estabelecido com firma comercial em Belém que, à data de abertura de seu inventário, em 1892, possuía 1200 ações da Companhia das Águas, tendo declarado ainda investimentos em imóveis em Portugal, 120 ações da Companhia Urbana, 2 ações da Companhia de Seguros Paraense, 100 ações do Banco Comercial do Pará, 307 letras hipotecárias, 5 apólices, 14 apólices do Estado do Pará e dinheiro ${ }^{49}$.

Cabe-nos ainda destacar a presença e representatividade das firmas comerciais como um dos investimentos mais expressivos, num total de 67 estabelecimentos, que atuavam em várias frentes, seja em pequenos comércios do varejo de mercadorias, livrarias, empresas de consignações e comissões,

${ }^{47}$ Renato Marcondes, "O Financiamento Hipotecário da Cafeicultura no Vale do Paraíba Paulista (1865-87)", Revista Brasileira de Economia, (2002) Janeiro/Março de 2002, p. 147.

${ }^{48}$ Renato Marcondes, "O Financiamento"... cit., p. 148.

${ }^{49}$ Inventário de Jose Augusto Correa, ano de 1892. Centro de Memória da Amazônia. 2. ${ }^{\text {a Vara }}$ Cível - Cartório Odon Rhossard. 
importados, entre outros. E, a maior parte destes empreendimentos ligada a indivíduos com montantes acima dos 100 contos de réis.

A Casa Pekin, sob a firma João Costa \& C $C^{a}$, era do português Jose da Costa Braga $^{50}$ e João Moreira Costa (nacionalidade desconhecida), especializada em louças, cristais, vidros e candeeiros, estabelecida na rua Conselheiro João Alfredo $n^{\circ}$ 96. A loja tinha seis sessões: louças e porcelanas, cristais e vidraçaria, lustres e candeeiros, christofle e eletro-plate (talheres, artigos de mesa, serviços para chá e café, porta joias e bibelôs), artigos de bohemia e vários artigos. Trabalhava com importações da França, Inglaterra, Alemanha, Áustria, China, Japão e América do Norte, e aceitava consignações de toda espécie. Considerada como um empreendimento "digno da prosperidade" pela qual passava a Amazônia, fazendo parte do livro "O Pará Commercial", distribuído na exposição de Paris de 1900, a fim de que fosse do conhecimento dos "países cultos o progresso e prosperidade do estado do Pará" ${ }^{51}$.

A Ribeiro da Silva \& Companhia, uma das maiores firmas de Belém, voltada para o comércio de ferragens e de aviamento, era propriedade de José Caetano Ribeiro da Silva ${ }^{52}$, matriculada na Junta Comercial do Pará em 1899, em sociedade com seu filho José Caetano Junior e com Antônio José Alves e Manoel Rodrigues de Santana, os dois últimos, respectivamente, português e brasileiro. Um elemento que nos chama atenção na composição da firma Ribeiro da Silva \& Companhia, é a presença de um sócio brasileiro, possivelmente paraense, o que poderia garantir à firma maior credibilidade, confiança no mercado da província, principalmente quando consideramos os conflitos que de antemão nortearam a relação entre portugueses e paraenses na primeira metade do século XIX que culminaram na Cabanagem ${ }^{53}$. Além disso, a presença de um sócio português nos leva a entender que, por estarem distantes de sua terra natal, os imigrantes ainda buscavam manter laços com seus conterrâneos, uma rede de solidariedade que também estreitava os laços com a terra natal.

${ }^{50}$ Inventário de Jose da Costa Braga, ano de 1903. Centro de Memória da Amazônia. 1. ${ }^{\text {a Vara }}$ Cível - Cartório Santiago.

${ }^{51}$ Arthur Caccavoni, Pará Commercial na Exposição de Paris, Pará, 1900, p. 5-30.

${ }^{52}$ Inventário de José Caetano Ribeiro da Silva, ano de 1900. Centro de Memória da Amazônia. 2. ${ }^{a}$ Vara Cível - Cartório Odon Rhossard.

${ }^{53}$ Revolução social que dizimou boa parte da população amazônica e abarcou um território muito amplo, entre os anos de 1835 e 1840. Contrastando com este cenário amplo e internacional, foi, e ainda é, analisada como mais um movimento regional típico do período regencial do Império do Brasil. A bandeira de luta dos levantados resumia-se na morte aos portugueses e aos maçons. 
Em seu inventário datado de 1900, José Caetano possuía uma fortuna calculada em 1.169:638\$819 contos de réis (45. $615 £$ ) composta por casas, num total de 18 unidades, terrenos, 2 unidades, e o capital proveniente da firma comercial. Percebemos, então, que a fortuna do dito português retrata a nova tendência de investimentos vigente na sociedade paraense, onde as estruturas ligadas à terra decrescem, dando espaço para os investimentos na cidade, principalmente em casas e terrenos em áreas de expansão do centro urbano.

O português também se destaca por sua atuação na Praça do Comércio, que mais tarde mudou seu nome para Associação Comercial do Pará, onde, ao lado do influente comerciante português Bento Rebello de Andrade, participou das reuniões que reorganizaram aquela associação, tendo seus nomes revezados nos seus diversos cargos, desde a presidência às diretorias ${ }^{54}$. A projeção de José Caetano também se estende à Beneficente Portuguesa, para onde foi eleito vice presidente em $1857^{55}$. Em 1858 foi eleito para a comissão julgadora das contas da diretoria da instituição beneficente. José Caetano ainda pode ser encontrado em notas de jornais locais como doador de valores para os náufragos do brigue português "Rocha", em $1859^{56}$, comprovando a rede de solidariedade que havia entre a comunidade portuguesa no Pará.

Além dos investimentos financeiros, encontrou-se uma variedade de bens móveis, como embarcações, móveis domésticos, joias e mercadorias, as últimas especialmente em inventários de comerciantes, como o processo inventarial do proprietário de uma livraria, o português Francisco Xavier Pinheiro Braga, onde se lê uma relação de vários livros ${ }^{57}$. Há ainda Manoel Joaquim de Souza, estabelecido com a firma comercial Moreira Gomes \& Companhia destinada à venda a grosso ou retalho de mercadorias e gêneros, especialmente ferragens, com trabalhos de compra e vendas, exportação e importação de ferragens, trânsito e comércio bancário, havendo a descrição de vários itens de ferragens no arrolamento de bens ${ }^{58}$.

A descrição desses bens materiais no decorrer dos anos vai sendo substituída pela citação ampla dos investimentos financeiros, que incluem ações, letras, apólices e outros, notadamente pela maior valorização destes em meio a um

${ }^{54}$ Cristina Cancela, Casamento e família..., cit., p. 366.

${ }^{55}$ História da Sociedade Portugueza Beneficente do Pará, cit., p. 28.

${ }^{56}$ Jornal Gazeta Official, 12 de Janeiro de 1859, p. 22.

${ }^{57}$ Inventário de Francisco Xavier Pinheiro Braga, ano de 1889. Centro de Memória da Amazônia. 11. ${ }^{\mathrm{a}}$ Vara Cível - Cartório Fabiliano Lobato.

${ }^{58}$ Inventário de Manoel Joaquim de Souza, ano de 1907. Centro de Memória da Amazônia. 11. ${ }^{a}$ Vara Cível - Cartório Fabiliano Lobato. 
contexto que vive intensamente as mudanças advindas da economia pulsante de exportação da borracha.

\section{Gráfico 3 - Bens Móveis - Materiais (Belém, 1870-1909)}

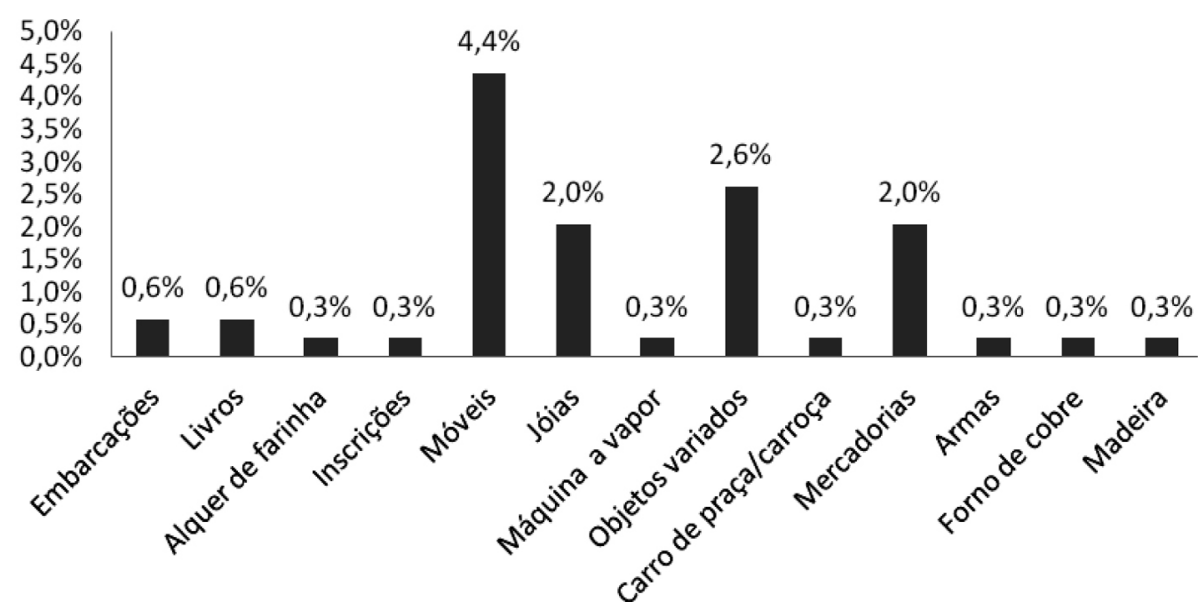

Fontes: Inventários post mortem do Centro de Memória da Amazônia. Cartórios

Santiago, Leão, Sarmento, Fabiliano Lobato e Odon Rhossard (1870-1909)

O número de proprietários de bens semoventes, sobretudo escravos e animais, ainda é expressivo, porém a posse de cativos negros já demonstra queda.

Entre junho de 1885 e maio de 1887, a taxa de declínio da população escrava no Grão Pará alcançou 47,9\%, diminuindo de 20.218 cativos para 10 . 535 cativos, sendo então a quinta maior do Império, atrás de localidades no Rio de Janeiro, Rio Grande do Sul, Paraíba e Paraná. Essas elevadas taxas de declínio podem ser explicadas como resultado de falecimento, pela aplicação da legislação emancipadora ou pelo avanço do abolicionismo nessas localidades nos anos finais da escravidão. Além disso, o número de ingênuos filhos de mulheres escravas libertos pela Lei do Ventre Livre, de 28 de setembro de 1871 até 30 de junho de 1885, na província paraense eram na ordem de 10.685 crianças; o numero das libertações dos escravos sexagenários no Pará, da ordem de 919 pessoas entre 1885 e 1887; o Fundo de Emancipação no Pará libertou mais de 687 indivíduos por alforrias pagas pelos escravos, e as concedidas pelos senhores, entre 1871 e 1885 , libertou 7.258 cativos $^{59}$.

\footnotetext{
${ }^{59}$ José Maia Bezerra Neto e José Maia, Escravidão negra no Grão Par, Belém, PakaTatu,
} 2001, p. 116. 
Os animais, em posse de 6 proprietários, se distribuem entre as fazendas e as quintas/sítios encontrados. São, sobretudo, gado vacum, garrotes e cavalares. Nesta amostra encontramos 13 proprietários de escravos que juntos possuíam um plantel com 42 indivíduos. A maior parte dos cativos, um número de 10, pertenciam ao comendador Joaquim da Silva Arantes, que possuía entre terrenos e casas, um sítio sem localização exata.

\section{Concluindo}

O destino do imigrante é construído em Belém pelas oportunidades que encontravam no momento da chegada. A formação de um patrimônio, em boa parte centrado na área urbana, indica a facilidade de acesso às áreas centrais, ao contrário dos espaços rurais, que centrados na mão de grupos estabelecidos bem antes de sua chegada, não foram igualmente disponíveis aos recém-chegados. Porém, este fato não isenta a ocorrência de portugueses com negócios ligados à terra, como exploramos anteriormente. Na Belém "rica", dos grandes seringalistas, dos "barões e viscondes", que crescia na economia, na população e no traçado urbano, os portugueses puderam projetar a sonhada "arvore das patacas", a fonte da riqueza, e dela se apropriaram de modo que se tornaram tão conhecidos e influentes quanto os naturais.

Entre os anos de 1869 e 1909, na Bélle Époque paraense, a área urbana da cidade já se mostrava mais desenvolvida, concentrando boa parte dos portugueses no setor terciário da economia. Observamos a ampliação nos investimentos em imóveis na cidade, entre casas e terrenos, a diminuição já esperada do acúmulo de cativos, e como novidade as estradas de seringa, em localidades do interior do estado, especialmente na região da Ilha do Marajó, onde desde o período colonial havia uma concentração de nacionais por conta das distribuições de sesmarias.

No mesmo período, os imóveis dividiam espaço com as dezenas de firmas, dezenas por vezes milhares de ações das mais variadas companhias e instituições bancárias, de clubes, de empresas de serviços públicos, que vieram junto à criação de uma Belém moderna, à altura da riqueza que a borracha garantia aos cofres da província, não à toa que o dinheiro corrente era elemento comum na maioria das heranças. As fortunas se concentram acima dos cem contos de réis, pertencentes a indivíduos atuantes no setor terciário da economia, reafirmando a importante participação que os portugueses tiveram para a consolidação de uma ampla rede comercial na cidade. 
Podemos afirmar, então, que a borracha teve papel importante para a elevação dos níveis e formas de alocação da riqueza entre os portugueses inventariados em Belém, sendo, inclusive, a maior responsável pelo enriquecimento de diversas famílias portuguesas ou mesmo de sujeitos isolados. Riqueza da borracha que se estendeu pelas vias públicas, pelas áreas de entretenimento, pelos portos, não se estendendo, porém, às demais parcelas da população.

Interessa-nos mencionar também a igualdade que pudemos observar entre os imigrantes e os nacionais quanto a aquisição de bens, mesmo havendo uma distribuição maior de terras entre nacionais, os portugueses ainda conseguiram arrematar posses nos interiores e mesmo nas áreas próximas à cidade. A participação em negócios no interior e nas cidades ainda demonstra a circularidade que estes sujeitos tinham entre as localidades, demostrando que sua condição de imigrante não fora um elemento regulador ou proibitivo para o estabelecimento de redes pessoais e profissionais.

Os bens adquiridos durante os anos de maior liquidez econômica puderam ser conservados mesmo durante a crise da economia da borracha, demonstrando estabilidade entre as estruturas econômicas e, consequentemente, nos negócios portugueses empreendidos em Belém durante a maior parte do século XIX e início do XX. 